\title{
Conduct disorder and future substance abuse: Factors affecting drug treatment outcome
}

\author{
Matthew E. Goldfine \\ West Virginia University
}

Follow this and additional works at: https://researchrepository.wvu.edu/etd

\section{Recommended Citation}

Goldfine, Matthew E., "Conduct disorder and future substance abuse: Factors affecting drug treatment outcome" (2006). Graduate Theses, Dissertations, and Problem Reports. 2480.

https://researchrepository.wvu.edu/etd/2480

This Thesis is protected by copyright and/or related rights. It has been brought to you by the The Research Repository @ WVU with permission from the rights-holder(s). You are free to use this Thesis in any way that is permitted by the copyright and related rights legislation that applies to your use. For other uses you must obtain permission from the rights-holder(s) directly, unless additional rights are indicated by a Creative Commons license in the record and/ or on the work itself. This Thesis has been accepted for inclusion in WVU Graduate Theses, Dissertations, and Problem Reports collection by an authorized administrator of The Research Repository @ WVU. For more information, please contact researchrepository@mail.wvu.edu. 
Conduct Disorder and Future Substance Abuse:

Factors Affecting Drug Treatment Outcome

Matthew E. Goldfine

Thesis submitted to the Eberly College of Arts and Sciences

at West Virginia University

in partial fulfillment of the requirements

for the degree of

Master of Science

in

Psychology

Steven A. Branstetter, Ph.D., Chair

Cheryl B. McNeil, Ph.D.

B. Kent Parker, Ph.D.

Department of Psychology

Morgantown, West Virginia

2006

Key words: Conduct Disorder, Severity, Violence, Substance Abuse, Treatment Outcome

Copyright 2006 Matthew E. Goldfine 


\section{ABSTRACT \\ Conduct Disorder and Future Substance Abuse: Factors Affecting Drug Treatment Outcome}

\section{Matthew E. Goldfine}

Prior research has demonstrated a relation between Conduct Disorder (CD), its severity (total number of symptoms), and substance use disorder (SUD). The current study examined 105 opioid dependent adults for a history of CD and treatment outcome characteristics over a 16 week SUD treatment program. Results demonstrate the effects of CD in regards to poorer improvement of summed Addiction Severity Index composite scores and amphetamine use. Improvement in cocaine use was found to be associated with a CD diagnosis. CD severity was found to lead to poorer improvement as measured by psychiatric impairment and alcohol intoxication. However, participants with increased CD severity were more likely to decrease sedative and cocaine use over the course of treatment. A history of CD and violent behavior was not shown to affect treatment outcome. No treatment retention or urine sample analyses differences were found among any of the comparison groups. 


\section{Acknowledgements}

This study was made possible as a result of a larger drug treatment outcome study conducted by Leslie Amass, Jonathan B. Kamien, and Steven A. Branstetter and supported by NIDA Grant DA11160. Additional support was garnered by West Virginia University’s Alumni Fund Research Award and Professional Research Milestone Award.

First and foremost, I wish to thank my mentor and thesis chair, Dr. Steven A. Branstetter. His investment in my professional development and dedication towards this project kept me motivated throughout the challenging research process. I also am appreciative of the guidance and support of my thesis committee members, Drs. Cheryl B. McNeil and B. Kent Parker.

Much of my success is due to the comradery and support I've received from my friends and family. I firmly believe that I have some of the best friends in the world and without them, I'm sure I'd be miserable. Thank you for the fun times and always making me laugh. Dad and Sara, you are both exceptional role models and have given me more love and encouragement than I could ever ask for. I am also incredibly thankful for my Mom and two wonderful sisters, Rachel and Arielle. Each of you has made me who I am today and I hope I've made you proud. Lastly, I wouldn't be here without my loving and caring girlfriend, Kelly. You are the love of my life and make me the happiest guy in the world. 


\section{Table of Contents}

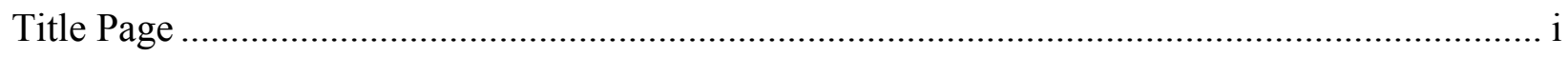

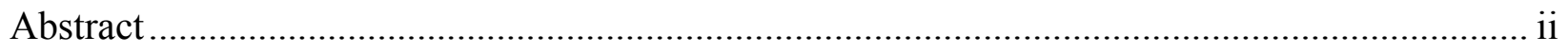

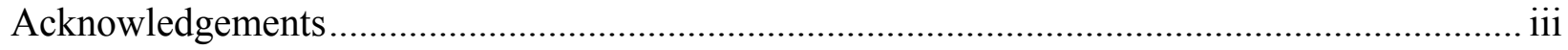

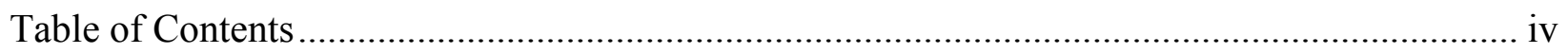

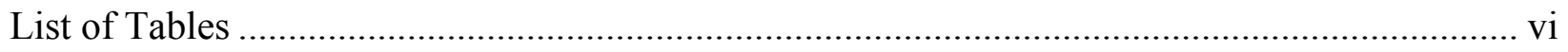

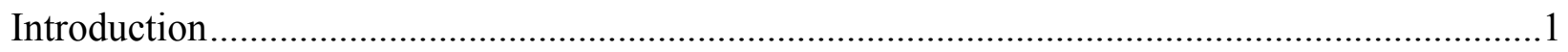

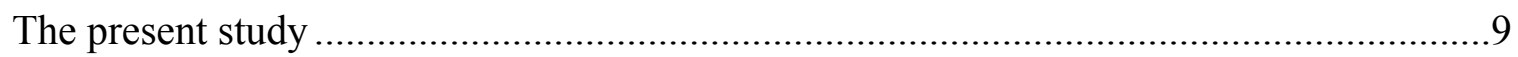

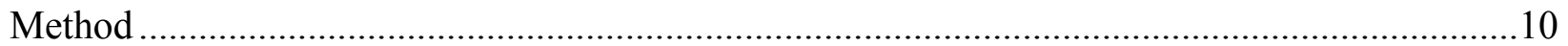

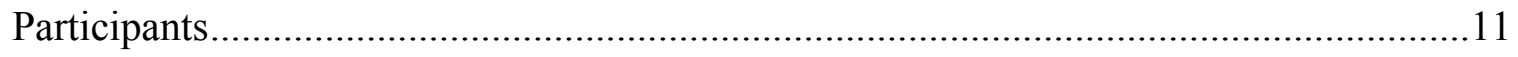

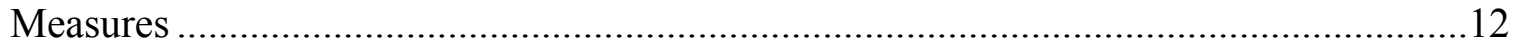

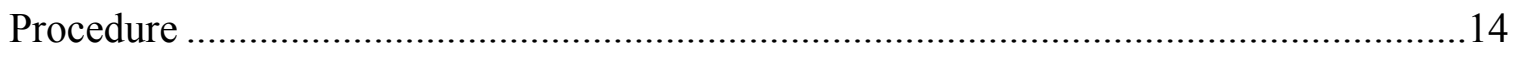

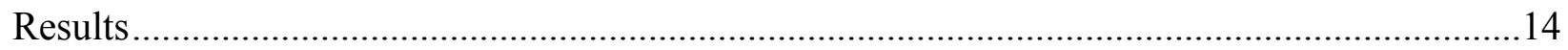

Participant dropout and correction of non-normal data characteristics .........................14

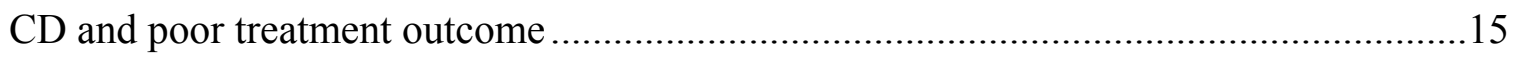

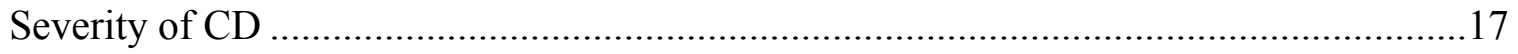

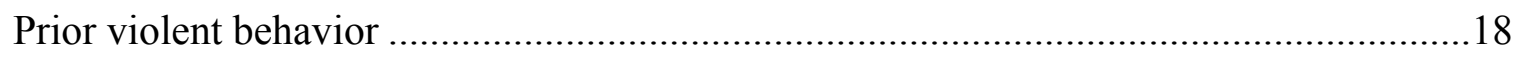

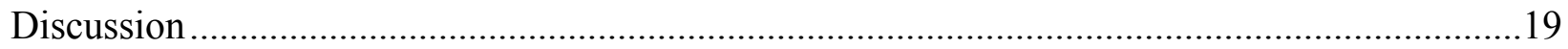

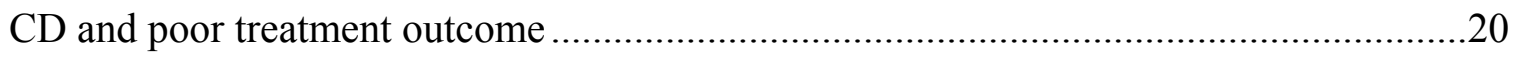

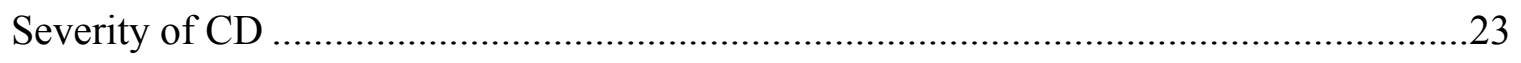

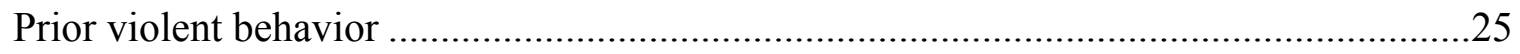

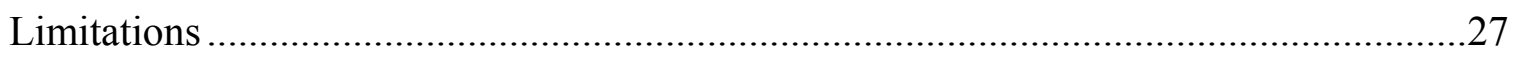

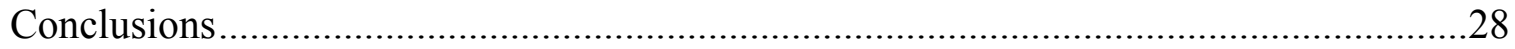




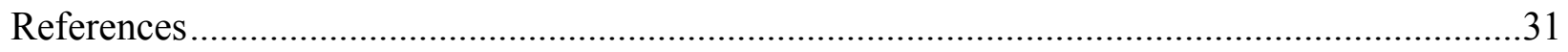

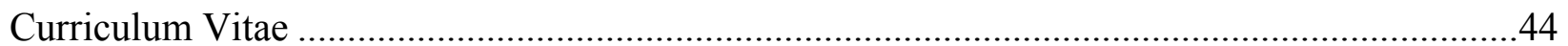




\section{List of Tables}

Table 1. Repeated-measures ANOVA of ASI composite scores over treatment, based upon CD diagnosis

Table 2. Repeated-measures ANOVA of drug use over the past 30 days based upon CD diagnosis (raw data)

Table 3. Hierarchical multiple regression of CD severity and ASI composite scores, controlling for intake scores

Table 4. Hierarchical multiple regression of CD severity and days of drug use over the past 30 days, controlling for use at intake

Table 5. Repeated measures ANOVA of ASI composite scores based upon prior violent, CDrelated behavior.

Table 6. Repeated measures ANOVA of drug use over the past 30 days based upon prior violent, CD-related behavior (raw data) 43 
Conduct Disorder and Future Substance Abuse:

Factors Affecting Drug Treatment Outcome

The presence of a comorbid mental health disorder among substance users has been shown to lead to higher rates of drug use, increased relapse rates, and overall poor treatment outcome (Tomlinson, Brown, \& Abrantes, 2004). Studies demonstrate that $64 \%$ of substance abusers have a lifetime comorbid Axis I disorder (Wise, Cuffe, \& Fischer, 2001). Often the most common comorbid Axis I disorder diagnosed among substance users is Conduct Disorder (CD; Grella et al., 2001). For instance, up to $52 \%$ of children and adolescents with CD will at some point meet criteria for a Substance Use Disorder (SUD; Reebye, Moretti, \& Lessard, 1995). Furthermore, substance users with CD tend to use and abuse drugs at higher rates than those with other comorbid disorders (Disney, Elkins, McGue, \& Iacono, 1999). Considering the ample support for the co-occurrence of CD and SUD (e.g., Armstrong \& Costello, 2002), there are relatively few studies which discuss how CD may influence the course of substance abuse or the prognosis for those with both CD and SUD. The present study further examined the association between $\mathrm{CD}$ and the functioning and treatment outcome among a population of opioid dependent adults seeking treatment.

The American Psychiatric Association's (APA) Diagnostic and Statistical Manual: $4^{\text {th }}$ edition, Text Revision (DSM-IV; 2000) defines CD as the persistent pattern of disregard for the basic rights of others. A diagnosis of CD is predictive of multiple negative outcomes, such as Adult Antisocial Personality Disorder (Ridenour et al., 2002), poor educational achievement, welfare dependency (Zoccolillo, Paquette, Azar, Cote, \& Tremblay, 2004), and adult criminality (Simonoff et al., 2004). However, there is large variation in the expression of CD symptoms among those who have been diagnosed. Four separate clusters of symptoms exist, including: 
aggression, property destruction, theft, and defiance of societal norms (APA, 2000). Only three of fifteen possible symptoms - from any of the above four clusters - are needed for diagnosis of CD. Thus, one who is truant from school, runs away from home, and frequently lies will have the same diagnosis as one who bullies others, has used a deadly weapon, and committed rape. The variability in the presenting symptoms of a $\mathrm{CD}$ diagnosis presents a problem for predicting how those with CD and an SUD may progress though substance abuse treatment and recovery. It seems unlikely that any and all combinations of symptoms would lead to similar substance use patterns and treatment outcomes. While no studies have directly measured the relation between SUD treatment outcomes and specific symptom clusters of $C D$, some researchers have investigated the relation between aggression, rape, truancy, and theft—all of which are CD symptoms - and found that each is uniquely predictive of SUD. If certain clusters of CD symptoms are stronger predictors of SUD development or treatment outcome, the dissemination of such knowledge would likely improve overall SUD prevention and treatment.

Prior to elaborating on the effect of specific CD symptoms on SUD, a relation between the two first must be established. In one study seeking to examine the deleterious consequences of CD on later adult functioning, Fergusson, Horwood, and Ridder (2005) investigated general adult functioning among participants who, as children, were assessed for various conduct problems. CD-like symptoms (but not a diagnosis of CD) at ages 7-9 were measured and various outcome data were collected regarding risky behavior at ages 21-25. At baseline, increased conduct problems were significantly correlated with lower IQ, lower socioeconomic status, and general family distress. Controlling for these possible confounding variables, the authors found an increased likelihood that the children with more CD-like symptoms at ages 7-9 were more involved with delinquency, risky sexual behavior, drug use, and internalizing disorders at ages 
21 - 25. Furthermore, while male and female differences were found concerning the average number of CD-like symptoms, the relation between childhood conduct problems and poor adult functioning remained the same. Although the study did not focus on substance abusing adults, it nevertheless supports the hypothesis that childhood conduct problems contribute to a range of negative outcomes in adulthood. Whitmore, Mikulich, Ehlers, and Crowley (2000) displayed similar support of gender's minimal effects on CD and SUD. The authors found that adolescent females with $\mathrm{CD}$ demonstrated similar drug use rates at intake as well as similar treatment outcomes to those of males with CD. It appears that both males and females with CD and SUD exhibit similar behaviors relating to overall functioning following treatment.

Whereas general adult functioning appears to be negatively impacted by $\mathrm{CD}$, there appears to be a particular link between CD and the development of SUD. In general, CD symptoms have been shown to precede the initiation of substance use (Hser, Grella, Collins, \& Teruya, 2003; Windle, 1990). In a longitudinal analysis of mental health disorders as predictors of future substance use, Boyle and colleagues (1992) found that only CD independently accounted for the future development of marijuana and hard drug use. This effect remained even when prior drug use was statistically controlled. Armstrong and Costello (2002) confirmed CD's link with future SUD and suggested that a diagnosis of CD is strongly related to earlier initiation of drug use and future SUD. Furthermore, Ridenour and colleagues (2002) found that not only does childhood CD predict later SUD problems, they also demonstrated that the age of onset of CD problems has little effect on future drug and alcohol-related symptoms; both childhood and adolescent onset CD are equally predictive of future SUD.

A number of studies have shown that $\mathrm{CD}$ is also a strong predictor of the use of specific substances, even when other possible constructs are statistically controlled. For example, in an 
investigation of CD symptoms in childhood, Fergusson, Lynskey, and Horwood (1993) found that cannabis use before the age of 15 was significantly correlated with parent and teacher report of $\mathrm{CD}$ symptoms at age 8 . Additionally, when variables such as family socioeconomic status and parental divorce and conflict were controlled, children with high ratings of CD-related symptoms were almost three times more likely to use cannabis than similarly aged children with fewer CD symptoms. Despite prior beliefs that CD's relation to later substance use was spurious and that other variables (family or social characteristics) were the cause of both, the authors concluded that conduct problems and not family or social characteristics significantly accounted for future cannabis use. In addition to cannabis, past studies have demonstrated that $\mathrm{CD}$ leads to higher rates of abusing alcohol (Myers, Brown, \& Mott, 1995), nicotine (Disney et al., 1999), cocaine, amphetamines (Whitmore et al., 2000), opioids, hallucinogens, and inhalants (Crowley, Mikulich, MacDonald, Young, \& Zerbe, 1998). In comparison to most recent prevalence measurements (Substance Abuse and Mental Health Services Administration, 2005), users with a history of CD are anywhere from 1.5 to 50 times as likely to use a harmful substance.

In addition to increasing the likelihood of substance use, a growing literature is suggesting that $\mathrm{CD}$ may predict poor outcome for those who enter treatment for a SUD. Hser and colleagues (2003) conducted one of the first studies to directly compare SUD treatment outcome among adolescents with CD. A total of 1031 adolescents treated for SUD were assessed for CD at intake and various treatment outcome measures were taken a year later. Patients with $\mathrm{CD}$ in an outpatient or short-term inpatient program were more likely to drop out of treatment than the unimpaired comparison group. Moreover, after treatment, the patients with $\mathrm{CD}$ were more likely than patients without $\mathrm{CD}$ to use marijuana and hallucinogens, perform illegal activities, and be 
arrested. These data demonstrate that after SUD treatment, adolescents with CD continue to engage in behavior detrimental to improvement at higher rates than adolescents without CD.

Another salient analysis discussing the relation of CD and SUD treatment includes Myers and colleagues' (1995) study measuring alcohol and drug abuse during adolescence. In this study, CD-related behaviors, the most common being deception or non-confrontational theft and the rarer being aggression, were typically exhibited before one's first substance use. The authors' main finding was that a history of CD-related symptoms leads to poor outcome in regards to post-treatment alcohol use, but not drug use. In other words, post-treatment rates of alcohol use differed among adolescents with and without preadolescent CD, but drug use rates did not statistically differ. Since post-treatment substance use was universally low for both groups, the lack of variation may explain treatment effects. A shortcoming of this study, as well as of the other studies discussed, is the lack of an evaluation of specific CD symptoms and SUD treatment outcome. In other words, these studies examine the relation between a diagnosis of CDregardless of the individual symptoms which comprise this diagnosis — and SUD development and treatment outcome. This raises the question of weather certain symptoms of CD (e.g., aggression) may be predictive of SUD treatment outcome whereas others (e.g., deceitfulness) may have little or no effect.

Continuing the scrutiny of CD and its characteristics which may affect SUD treatment is a study conducted by Crowley and colleagues (1998). The authors break down features of CD, such as its severity and age of onset, and analyze how each may predict maladaptive behavior after receiving SUD treatment. Adolescent males were assessed through a series of intake measures which included a diagnostic interview, depression assessment, and a drug use query. Participants were then followed-up at 6, 12 and 24 months after admission using similar 
evaluations. It was found that intake CD severity, that is, the total number of CD symptoms, was related to CD symptoms two years later. The authors concluded that increased CD symptoms led to poorer outcome two years after treatment. Similarly, earlier onset of CD, predicted overall criminal activity and delinquent behavior. Whereas Attention-Deficit/Hyperactivity Disorder (ADHD) and depression severity were also measured, only CD variables led to negative outcome in adolescent substance abusers.

While Crowley and colleagues (1998) measured accompanying features of CD, the literature has begun to measure specific CD symptoms and the effect on the development and treatment of SUD. Among the many individual symptoms of CD which may lead to SUD, aggression and violence appear to be particularly powerful predictors. Burr (1987) reports a theoretical model which appears to have support within the literature. Namely, that violent behavior leads to future SUD. Burr theorizes that aggressive individuals often lead a lifestyle of criminality in which alcohol and drug use are common. Since the individual is already engaging in harmful behavior (violence), substance use is appealing because such activities correspond with a delinquent lifestyle. Johnston, O’Malley, and Eveland (1978) elaborate, claiming that violent characteristics lead one to spend time in an environment with other violent individuals where drug use is both expected and reinforced. Evidence confirming the link between violent behavior and future substance use is ample and often builds upon a study by White, Brick, and Hansell (1993). Over the course of nine years, 431 adolescents, 12 years-old at the start of assessment, were monitored for aggressive behavior (e.g., number of fights, use of a weapon) and alcohol use (e.g., drinking frequency, amount consumed). While alcohol use did not predict future aggression, violent behavior was shown to lead to increased alcohol use at an older age. 
Further support of the predictive strength of childhood aggression to later SUD is demonstrated by Brook, Whiteman, Finch, and Cohen (1996). Pre-adulthood variables were measured over the course of a 20 year study to discern meaningful predictors of adult drug use. Childhood aggression, as measured by mother report, foreshadowed future adult substance use in both males and females. Kellam and Brown (1982) and Lewis, Robins, and Rice (1985) also support similar results. Both studies measured aggression in young children and found that it predicted adolescent and adulthood SUD. O'Donnell, Hawkins, and Abbott (1995), concluded similarly, but noted that not all aggressive children develop adult SUD. In other words, there are other specific qualities of the child or aggressive behavior that may contribute to one's future outcome. It may be that frequency of aggressive symptoms or varied forms of aggression are better predictors than violent behavior in general.

An example of an alternate form of violence is sexual assault or rape. Although little research has been done regarding the link between committing rape and substance abuse, a preliminary study (Abracen, Looman, \& Anderson, 2000) compared sexually and non-sexually aggressive adults and their rates of alcohol and overall substance use. Although the temporal occurrence of the violence and alcoholism was difficult to distinguish, sexual offenders had higher rates of alcohol abuse than aggressive adults who have not engaged in prior sexual assault. Given that aggression alone is a risk factor for adult alcoholism (White et al., 1993) and sexual offenders have an even higher rate of alcoholism than non-sexual violent offenders, sexual violence, such as rape, which is one of the violent cluster symptoms of $\mathrm{CD}$, may have a unique association with future alcoholism.

Aggressive behavior is one of only a few specific CD symptoms demonstrated to predict SUD over time. However, there is also evidence that truancy and running away, both listed 
within the defiance of social norms cluster of CD symptoms (APA, 2000), may be risk factors for future drug use and abuse. Truancy, or the act of missing school without parental permission (sometimes referred to as playing hooky), has been shown to be highly correlated with the use of cigarettes, alcohol, marijuana, cocaine, and other illicit substances. Miller and Plant (1999) studied 15-16 year-old adolescents from the United Kingdom and their truant behavior over the past month and lifetime alcohol, cigarette, inhalant, cannabis, and other drug use. For all substances, a significant association was found between drug use and truant behavior such that higher rates of missing school was correlated with higher rates of substance use. While there were other measured factors, such as parental discipline and style, which may also have accounted for increased substance use, truancy appears to be a relevant variable in the relation. Adding to the evidence demonstrating the effects of truant behavior on SUD is Brown, Schulenberg, Bachman, O’Malley, and Johnston's (2001) analysis of about 188,000 high school seniors from 1976-97. Despite possible cohort differences, truancy was a fairly consistent predictor of cigarette, alcohol, marijuana, and cocaine use. The authors added that these results with such a large sample size reflect with confidence that truancy is a significant risk factor for SUD and treating truant individuals may be an important aspect of preventing and treating substance use. A caveat in both studies is that the participants' age ranged from 15-18 years old. Diagnostic criteria for CD specify that these behaviors must occur prior to age 13. However, no data were collected prior to that critical age.

In a review of adolescents who run away from home, Brennan, Hulzinga, and Elliot (1978) discuss substance abuse among this population. Before and during the act of running away, substance use is quite common and runaways may become drug dealers as a way of financial support. While there is a correlation between running away and SUD, it may be that 
substance use and running away affect one another in a bidirectional manner. For example, the act of running away may lead one to be more involved within the drug culture while substance use may also be an indicator of general delinquency which leads one to leave home (and its rules) in order to continue deviant behavior. Similarly, delinquent behavior involving theft, another symptom cluster of CD, and SUD has also been theorized to exist in a reciprocal manner. Mason and Windle (2002) analyzed over 1,200 adolescents and found that such a bidirectional theory was supported for males. General delinquent behavior, such as theft, accounted for a minimal, yet significant, variance of one's substance use, which, in turn, was predictive of continued future delinquency. The conclusion that theft may have only a small effect on future substance use is a noteworthy finding. It may be that theft-related symptoms of CD are not as relevant as aggression or truancy in predicting future substance abuse or SUD treatment outcome.

The Present Study

Throughout the CD literature, there appears to be strong support regarding the effect of CD on SUD development and treatment outcome. Boyle and colleagues (1992), recognizing this association, declared that it is imperative for future SUD studies to incorporate aspects of CD into their design. Despite strong recommendations and seemingly high clinical utility, no research could be found investigating specific or clusters of symptoms of CD and their predictive strength for SUD treatment outcome. Generally, studies assess the presence or absence of a CD diagnosis. Given the wide variation within a CD diagnosis, it would appear to be beneficial to identify specific clusters of symptoms that are related to the development and treatment of SUD. In an effort to build upon past research and to confirm past findings, the present study examined the relation between CD, its severity, and aggressive symptoms and SUD treatment outcome. 
The goals of the study were threefold: (1) Determine if a diagnosis of CD leads to poorer SUD treatment outcome than the absence of CD, (2) Examine if the number of CD symptoms (severity) is predictive of poor treatment outcome, and (3) Analyze participants who exhibit CD with violent or aggressive symptoms versus those without such symptoms and their treatment outcome. The first two goals intended to replicate past studies. Namely, Hser and colleagues (2003) and Crowley and colleagues (1998) supported that a CD diagnosis and increased CD severity are linked with poor SUD treatment outcome, respectively. Regarding the third aim, in accordance with Loeber and colleagues' (1995) findings that physical aggression, as opposed to other CD symptoms, were predictive of future CD development, it was expected that a history of violent $\mathrm{CD}$ symptoms, such as aggression towards peers or animals, would be more indicative of poorer adjustment and treatment outcome than would its absence. Additionally, the present study sought to examine a range of treatment outcome dimensions, including treatment retention and adherence, drug use, and functioning across several domains, including social, occupational, and psychiatric. It is important to note that in addition to comparing variables pre- and posttreatment, adjustment to treatment was also included in the analyses. That is, data were collected at intake, during, and at the termination of treatment. As such, the term treatment outcome refers to functioning during and at the conclusion of treatment.

Method

The data used for the current study were collected as part of a larger opioid treatment project (Amass, Kamien, Branstetter, \& Mikulich, 2000) in collaboration with the University of Colorado Health Science Center. From July 17, 1997 through September 3, 1999, the study was conducted at The Vine Street Center, an adult opioid outpatient treatment program located in Denver, Colorado. All data, including the data for the present study, were entered into the 
database without any protected health information (PHI) from which the participants could be directly identified.

The project was a 16 week double-blind, double-dummy, randomized clinical trial evaluating the effects of pharmacological treatments on opioid dependence. Minimum likelihood allocation was used to randomly assign participants into one of four groups evaluating the effects of: (1) $8 \mathrm{mg}$ of buprenorphine and $2 \mathrm{mg}$ naloxone; (2) $16 \mathrm{mg}$ buprenorphine and $4 \mathrm{mg}$ naloxone; (3) $45 \mathrm{mg}$ methadone; and (4) $90 \mathrm{mg}$ methadone. Additionally, all participants received an hour of individualized behavioral counseling every week for the duration of the study and were offered group counseling sessions as well.

\section{Participants}

One-hundred-five adults ( 85 male), solicited through Denver newspaper, poster advertisements, and referred from similar local treatment programs consented to participate in the study. In order to qualify, all individuals were required to be at least 18 years-old, in good health, and meet DSM-IV criteria for opioid dependence and FDA criteria for methadone treatment. Participants currently using heroin, prescription opioids, or receiving methadone maintenance treatment were included. Exclusion criteria included active psychosis, bipolar symptoms, organic psychiatric disorders, or significant medical illness. Participants were also permitted from participating if they were prescribed mediation which potentially could be abused. After being informed of the study and its respective protocol, participants provided written informed consent. The mean age of the sample was 39.6 years $(S D=10.8)$ with a range of 18 to 63 years of age at intake. The sample consisted of 53\% Caucasian, 26\% Latino, 20\% African-American, and 1\% Asian or Pacific Islander. Years of opiate use ranged from 1 to 43 years, $(M=11.7, S D=10.8)$. A total of $66 \%$ of the participants were legally employed and $72 \%$ 
had a history of methadone treatment. Thirty-eight percent of the sample were never married, $28 \%$ divorced, $19 \%$ married, $11 \%$ separated, and $5 \%$ widowed.

As indicated by the diagnostic interview, 63 of the 105 participants (60\%) qualified for a childhood CD diagnosis. Of the participants with $\mathrm{CD}, 39$ of 63 (62\%) reported prior aggressive symptoms and were classified as violent CD. As a result of participant dropout, 57 of 105 participants remained at 8 weeks and 50 remained at the conclusion of the 16 week treatment. Measures

Diagnostic Interview. Portions of the Diagnostic Interview Schedule for DSM-IV diagnosis (DIS-IV; Robins, Cottler, Bucholz, Compton, \& Rourke, 2000) were conducted for all participants to assess for Conduct Disorder (Section O). Participants completed a face-to-face interview conducted by certified addiction clinicians. The DIS-IV is a structured diagnostic interview characterized by short, simple questions which can typically be answered with a 'yes' or 'no' response. Participants were given ten dollars upon successful completion of the interview. In previous studies, test-retest reliability for the DIS-IV ranged from satisfactory to excellent and there was good agreement with versions of the DIS and separate clinician diagnosis (Helzer et al., 1985). Forms of the DIS have been used in multiple past studies in order to accurately diagnose CD and Antisocial Personality Disorder (i.e., Ridenour et al., 2002; Darke, Kaye, \& Finlay-Jones, 1998).

Substance Abuse. Computerized versions of the psychoactive substance disorder sections of the DSM-IV Criteria Checklist (modified from Hudziak et al., 1993) were administered in order to assess for opioid dependence. The checklist is a semi-structured evaluation shown to accurately assess major DSM-IV mental health disorders. It has been shown to demonstrate acceptable diagnostic agreement with other validated mental health evaluations (Janca, Robins, 
Bucholz, Early, \& Shayka, 1992). Only participants meeting for opioid dependence were permitted to participate in the study.

Addiction Severity. The fifth edition of the Addiction Severity Index (ASI; McLellan et al., 1992) was administered. The ASI is a semi-structured interview designed to assess a range of symptoms and behaviors of drug and alcohol users. Additionally, demographic variables, such as age, race, and religious preference are also queried with this measure. One can typically administer the 161 item index in 30-45 minutes. The ASI assesses functioning in six areas: (1) medical, (2) employment/support, (3) alcohol/drug use, (4) legal, (5) family/social relationships, and (6) psychiatric. The ASI yields composite scores for each areas ranging from 0 to 1 , with higher scores indicating more severe impairment. Given the nature of the present study, separate ASI scores were calculated for alcohol and drug use. Studies have demonstrated high levels of internal consistency (.68), test-retest reliability (.92), inter-rater reliability (up to .96 ), correlations with other measures of SUD and impairment (up to .73), and sensitivity and specificity for alcohol (.84 and .93 , respectively) and drug abuse (.91 and .92 , respectively; McLellan et al., 1985; Hodgins \& el-Guebaly, 1992; Appleby, Dyson, Altman, \& Luchins, 1997). The ASI was administered at intake, 8 weeks, and 16 weeks into the study.

Urine Sample Analysis. Three times each week, urine samples were collected. Each of the samples was analyzed for the presence of opioids. Once each week, one of the following substances was randomly chosen to be analyzed as part of the urine sample: cocaine metabolites, amphetamines, benzodiazepines, barbiturates, or cannabinoids. To measure opioid abstinence, number of opioid-negative urine samples ("clean" samples) and ratio of negative samples to total samples scheduled (absent samples included) were calculated. 
Treatment Retention. Treatment retention was calculated as the number of days each participant remained active in the study.

\section{Procedure}

Prior to enrollment, participants completed a comprehensive intake interview to determine study eligibility and were administered the ASI. This interview was conducted in a two to three hour session the day of enrollment and completed on the same or next day. Data regarding treatment adjustment were collected throughout the study and calculated following participant completion. The DIS-IV was administered during the first two weeks of study participation and ten dollars was given upon its completion.

Results

\section{Participant dropout and correction of non-normal data characteristics}

Of the 105 participants screened at intake, 57 remained after 8 weeks and 50 remained for the complete 16-week treatment program. Given the missing data resulting from a high rate of dropout (52\%) and potential abnormal distributions, results were examined for any non-normal characteristics.

All data were initially screened for the presence of outliers and problems of skew or kurtosis. Data identified as outliers were reassigned to a value equaling the $75^{\text {th }}$ percentile of the distribution plus 1.5 times the interquartile range. For outliers falling below the $25^{\text {th }}$ percentile, the same formula was used with the $25^{\text {th }}$ percentile replacing the $75^{\text {th }}$ percentile and subtraction in place of addition. Next, using procedures advocated by Behrens (1997), variables with a skew greater than 3 or kurtosis greater than 10 were transformed using either inverse, inverse squared, square root, $\log 10$, or $\log$ e transformations. These transformations resulted in more normally distributed scores with acceptable skew and kurtosis. 
A return-to-baseline technique was used for all missing data. It assumes that once no longer receiving treatment, the participant's scores and drug use will regress to the assessed pretreatment intake figure. The return-to-baseline procedure is a highly conservative estimate for accounting for missing data as it is based on the assumption that individuals who drop out of a SUD treatment program, are likely to relapse to pretreatment substance use rates. This method of imputing missing data, unlike similar methods (e.g., last value carried forward), assumes that those who drop out of treatment do not sustain any gains they made during the course of treatment because dropout from such programs often indicate full relapse. This method for missing data imputation was selected for several reasons. First, evidence has emerged which suggests that traditional methods of dealing with missing data (e.g., listwise-deletion) can result in "drastically changed magnitudes or incorrect signs of the estimates of causal effects or descriptive inferences” (King, Honaker, Joseph, \& Scheve, 1998, p. 4) and can result in discarding a large portion of useful data (Duncan, Duncan, \& Strycker, 2006). Additionally, this method was selected because common methods of estimating a missing value (e.g., group mean) use no information specific to the individual missing the data and have also been shown to result in biased estimates (Engels \& Diehr, 2003). Because of these findings, the return-to-baseline method was selected as the most conservative estimation for missing data imputation using values based on each individual and not group means or values.

\section{CD and Poor Treatment Outcome}

ASI scores. A repeated-measures analysis of variance (ANOVA) was performed to examine differences in summed and ASI composite scores over time among participants with ( $n$ $=63)$ and without $(n=42)$ a CD diagnosis. A significant effect of time was found for summed ASI score, $F(2,102)=7.68, p<.01$. Such an improvement was expected given the treatment 
received by the participants. An interaction effect of Summed ASI Score X CD diagnosis was found to approach significance, $F(2,102)=2.49, p=.09$. Follow-up tests indicate that participants without CD significantly improved from intake to 16 weeks where those with CD did not improve. Approaching significance, intake employment/support composites among CD participants indicated higher scores prior to treatment, $F(1,103)=2.86, p=.09$. Refer to Table 1 for comprehensive results.

Drug use. A repeated-measures ANOVA was conducted to evaluate differences in drug use among participants with and without a CD diagnosis throughout the 16-week treatment period. As illustrated in Table 2, over the course of treatment, there was a significant interaction effect of Cocaine Use X CD Diagnosis, $F(2,102)=4.00, p<.05$. Pairwise comparison followup tests indicated that participants with CD improved from intake to 8 weeks where those without CD did not improve markedly throughout treatment. However, among both comparison groups, there were no differences in intake cocaine use and use at the conclusion of treatment. Similarly, there was an Amphetamine Use X CD Diagnosis interaction effect which approached significance, $F(2,102)=2.54, p=.08$. However, contrary to cocaine use, follow-up tests demonstrated that the absence of a CD diagnosis led to amphetamine use improvement from 8 to 16 weeks where a CD diagnosis indicated no improvement over the course of treatment. A oneway ANOVA demonstrated differences approaching significance in sedative use over the 30 days prior to intake. Participants without CD reported using sedatives more frequently, $F$ (1, $102)=3.03, p=.09$.

Treatment retention and urine analyses. A one-way ANOVA was conducted to examine differences between treatment retention and urine sample analyses among participants with and without a CD diagnosis. No significant differences were found between treatment retention rates 
of the two groups, $F(1,103)=.11, p=.74$. An analysis of the means and standard deviations indicate a high rate of variability in the treatment retention of participants with $\mathrm{CD}(M=75.8$ days; $S D=47.6$ days $)$ and without $\mathrm{CD}(M=78.9 ; S D=43.0)$. The large range in dropout $(R=$ 113 and 110 days, respectively) may have also contributed to the results. Similarly, no significant differences were found in the number of clean urine samples or percentage of clean urine samples provided, $F(1,103)=.07, p=.79$ and $F(1,103)=.00, p=1.00$, respectively. Similar to treatment outcome, there were high rates of variability, with the standard deviation approaching or greater than the mean.

\section{Severity of $C D$}

ASI scores. A hierarchical multiple regression analysis was conducted to analyze the effect of number of CD symptoms on ASI composite scores at the conclusion of the 16-week treatment, controlling for intake scores. Table 3 demonstrates that CD severity was shown to significantly affect ASI psychiatric composite scores, $F(1,101)=4.20, p<.05, R^{2}$ change $=.02$, final model $R^{2}=.57$. Beta weights indicate that as CD severity increases, so does psychiatricrelated impairment, $\beta=.13$. A linear regression was conducted to determine the effect of number of CD symptoms to intake ASI composites. CD severity was found to positively relate to intake employment/support composite scores, $F(1,103)=6.37, \mathrm{p}=.01$, adjusted $R^{2}=.05, \beta=.24$.

Drug use. A hierarchical multiple regression analysis was conducted in order to calculate the relative influence of $\mathrm{CD}$ symptoms on drug use from intake to 16 weeks while controlling for intake drug use. Results indicate that the number of CD symptoms was positively associated with rates of alcohol intoxication, independent of use at intake, $F(1,102)=6.26, p=.01, R^{2}$ change $=$ .03 , final model $R^{2}=.52, \beta=.17$. The effect of CD severity on sedative and cocaine use approached significance, $F(1,101)=3.04, p=.08, R^{2}$ change $=.02$, final model adjusted $R^{2}=$ 
$.33, \beta=-.14$ and $F(1,102)=2.82, p=.10, R^{2}$ change $=.01$, final model adjusted $R^{2}=.51, \beta=-$

.12 , respectively. As the number of CD symptoms increased, sedative and cocaine use were more likely to decrease. A linear regression analysis did not find any link between CD severity and drug use recorded at intake.

Treatment retention and urine analyses. A linear regression was conducted to determine the relation of $\mathrm{CD}$ severity on treatment retention. Treatment retention was not shown to be related to CD severity, $F(1,103)=.88, p=.35$. Similarly, $\mathrm{CD}$ severity was not shown to predict number of clean urine samples or percentage of clean urine samples provided, $F(1,103)=.03, p$ $=.86$ and $F(1,103)=.04, p=.85$, respectively.

\section{Prior Violent Behavior}

ASI scores. All participants qualifying for a childhood CD diagnosis were categorized as either violent $(n=39)$ or nonviolent $(n=24)$ based upon a history of aggressive behavior as measured by diagnostic report. A one-way ANOVA was utilized to compare the number of CD symptoms among participants with violent or nonviolent CD. Violent CD participants had significantly more CD symptoms than the nonviolent CD participants, with means of $6.03(S D=$ $2.20)$ and $4.04(S D=1.02)$ symptoms, respectively, $F(1,60)=17.96, p=.00$. A repeatedmeasures ANOVA was conducted in order to examine differences in ASI scores over time among participants classified with violent or nonviolent CD. There was shown to be a main effect of time, as summed ASI scores generally decreased over time for both groups, $F(2,59)=$ $3.78, p<.05$. Table 5 illustrates that no improvement differences were found between the two groups' summed ASI scores over time, $F(2,59)=.20, p=.82$ or among any ASI composite scores. A one-way ANOVA was conducted and found significant differences in the employment/support composite scores at intake, $F(1,60)=4.01, p=.05$ with the violent $\mathrm{CD}$ 
group obtaining higher scores, indicating more impairment. Moreover, differences in the psychiatric composite at intake approached significance, $F(1,60)=3.38, p=.07$ with the nonviolent $\mathrm{CD}$ group obtaining higher scores.

Drug use. A repeated-measures ANOVA was conducted to evaluate differences in drug use of participants with violent and nonviolent $\mathrm{CD}$ over the course of treatment. Table 6 displays no significant differences between the two groups regarding drug use improvement. Differences in cocaine use prior to intake approached significance, $F(1,60)=3.15, p=.08$. Participants classified with violent $\mathrm{CD}$ used cocaine less frequently than participants with nonviolent CD. Otherwise, no differences were found regarding drug use at intake among participants with violent and nonviolent CD.

Treatment retention and urine analyses. A one-way ANOVA was conducted to examine any differences between treatment retention and urine sample analyses among participants with violent or nonviolent CD. No significant differences were found between treatment retention rates of the two CD groups, $F(1,60)=.33, p=.57$. Additionally, no differences were found in the number of clean urine samples or percentage of clean samples provided, $F(1,60)=.01, p=$ .91 and $F(1,60)=.00, p=.99$, respectively. As discussed in the analysis of the effects of a CD diagnosis, due to the large range of dropout, considerable variability was present in these results, which may help clarify the low $F$ values.

\section{Discussion}

As part of a drug treatment program, opioid dependent adults were given a diagnostic interview to determine if, as a child, they qualified for a CD diagnosis. Data regarding CD diagnosis, number of CD symptoms, and prior aggressive behavior were evaluated with multiple treatment outcome variables. In accordance with Hser and colleagues (2003), there were 
supporting data that over the course of treatment, participants with $\mathrm{CD}$ experienced poorer improvement from intake to the end of treatment in regards to summed ASI scores and better improvement from intake to 8 weeks concerning cocaine use. As one's CD severity increased, psychiatric related impairment, as measured by ASI composite scores, increased as well. Additionally, more CD symptoms led to poorer rates of alcohol intoxication improvement and better improvement for sedative and cocaine use. In comparing participants with $\mathrm{CD}$ with and without a history of violent behavior, there did not appear to be any differences in treatment outcome, although participants with prior violent behavior did on average report more CD symptoms. In general, there is support that a history of $\mathrm{CD}$ and/or increased number of $\mathrm{CD}$ symptoms may lead to different presenting and treatment outcome characteristics, both positive and negative, than a comparison group. While not varying in treatment outcome, participants with a history of $\mathrm{CD}$ and prior violent behavior were found to have different intake characteristics than participants with a history of $\mathrm{CD}$ in the absence of aggressive behavior.

\section{$C D$ and Poor Treatment Outcome}

Prior to any intervention, differences emerged demonstrating an association between participants with CD and increased ASI employment/support composite scores and sedative use over the 30 days prior to intake. It may be that childhood CD symptoms, such as violence towards others, stealing, or lying may still presently occur and would likely make it difficult to attain a job and support one's self, thus leading to low scores on the respective ASI composite. The employment/support composite, contrary to most other ASI queries, may rely on personal attributes such as interpersonal trust and reliability which may be difficult to obtain if one is behaving in accordance with CD symptoms. Regarding sedative use, it may be that the calming and tranquilizing nature of sedatives are more attractive to the $\mathrm{CD}$ population. These effects may 
be a desirable contrast to the potentially aggressive or hostile cognitions and behaviors that may accompany CD. Needless to say, in order to better understand this relation, additional studies are to be conducted in this area of research.

ASI scores. Over the course of the 16-week treatment, differences were found in improvement rates of summed ASI composite scores between participants with and without CD. It may be that the groups' differing incoming characteristics led to improvement variation during SUD treatment. Given the presenting impairment in the employment/support domain, it can be theorized that the lack of a steady job or an ability to support one's basic needs may have prevented participants with $\mathrm{CD}$ from retaining improvement over treatment. In the absence of the stability of a daily routine, other facets of one's life, as measured by the ASI, may also suffer. Another explanation may be that participants with a history of CD continue to perform the respective maladaptive behaviors and this is reflected in the composite scores of the ASI. For instance, participants continuing to present with theft will have difficulties in the legal domain or those defying major societal norms may experience impairment with family and social relationships. Cumulatively, relatively poor improvement of ASI scores demonstrate that SUD treatment was not as effective for participants with $\mathrm{CD}$ in reducing drug and alcohol related impairment as compared to those without $\mathrm{CD}$.

Drug use. Over the course of treatment, results demonstrated different improvement rates of amphetamine and cocaine use as a function of a $\mathrm{CD}$ diagnosis. Regarding cocaine use, participants with $\mathrm{CD}$ underwent improvement from intake to 8 weeks of treatment, while the same population had poorer amphetamine use improvement rates from 8 to 16 weeks in comparison to candidates without CD. Perhaps the high likelihood of comorbid CD and ADHD (McMahon \& Wells, 1998) in childhood may be involved in the variation of amphetamine use. 
Since many psychotropic medications for ADHD are classified as amphetamines (e.g., Adderall) and demonstrated to be effective in treating ADHD symptoms (James et al., 2001), the benefits of amphetamines may outweigh some of the risks and thus, reducing its use may not be considered as beneficial. Considering CD symptoms are often seen with ADHD, long-term amphetamine treatment may be more difficult to obtain with conventional drug treatment. Indeed, a 28 year longitudinal study found a significant correlation between an ADHD diagnosis and amphetamine dependency (Lambert, 2005). Even when controlling for other possible confounding variables, children with ADHD were more likely to become addicted to amphetamines than peers without ADHD. However, that same study also found no significant relation between childhood conduct problems and amphetamine use.

A theory to explain greater cocaine use improvement among participants with $\mathrm{CD}$ may be the effects of a limited budget. As represented by higher impairment in the employment/support domain, participants with $\mathrm{CD}$ reported more difficulties supporting themselves financially. Without sufficient monetary support, purchasing cocaine may be more difficult and lead to amplified financial difficulties. Thus, this population may be more receptive to drug treatment and the monetary gains experienced accordingly may provide additional motivation to reduce its use. As such, Cleveland (2006) concluded that hard-core drug users are especially responsive to the overall cost of their drug of choice and will increase or decrease their use accordingly. Surely, more research needs to be done on this topic, but variations among presenting employment/support impairment may help explain the different results among the two populations.

General conclusions. Given the limited differences at intake regarding ASI scores and drug use over the past 30 days, it appears that within the population of substance abusers seeking 
treatment, a diagnosis of CD may not exert as much influence as established in past studies. An explanation for this may be the nature of the comparison group. In past studies (e.g., Fergusson et al., 1993), researchers compared participants with CD to relatively unimpaired individuals. However, in the current study, all participants were opioid dependent and most reported a history of psychological, social, and emotional impairment. Thus, discriminating the groups based upon CD may not lead to as much measurable differences between the groups as in past studies, based upon the history of the participant pool. This may also play a part in explaining why the CD group unexpectedly improved in certain measures (e.g., cocaine use). Within this population, perhaps a diagnosis of CD only alters outcome in very specific aspects of SUD treatment. Severity of $C D$

ASI scores. As Crowley and colleagues (1998) reported, as the number of CD symptoms, or severity, increases, one's treatment outcome is likely to worsen. To a degree, these results were supported by the current study. In addition to incoming differences within the employment/support composite, participants with more severe CD obtained significantly higher ASI psychiatric composite scores over the course of treatment. The psychiatric composite results are plausible; reporting more $\mathrm{CD}$ symptoms appears to demonstrate more mental health difficulties which may not be as receptive to treatment. With this impairment, a prospective employer may be less likely to hire or continue to retain a staff member displaying these maladaptive symptoms. Such results suggest that altering treatment to emphasize improvement within the psychiatric and employment/support domains may be a beneficial addition to conventional substance abuse treatment for participants with high CD severity.

Drug use. With additional CD symptoms, researchers were more likely to observe a reduction in cocaine and sedative use over the course of treatment. If there is validity to the 
hypothesis that differences in the employment/support domain at intake led to financial restrictions, then particularly expensive drugs, such as cocaine and sedatives, would be more likely to improve. Decreasing cocaine and sedative use may be more appealing to participants with increased CD symptoms due to presenting difficulties in the ability to support one's self.

Alcohol intoxication rates, on the other hand, increased along with CD severity. Possibly there is a certain effect of alcohol intoxication which is appealing to participants with many $\mathrm{CD}$ symptoms. A viable explanation is that alcohol, in contrast to the other drugs assessed, can be legally used as a mean to intoxicate one's self. Participants with high CD severity may have been more likely to substitute alcohol in place of other drugs, namely heroin. Since all participants were opioid dependent and opioid use generally decreased over the course of treatment, it is theorized that those with more CD symptoms (and higher impairment) coped with their withdrawal through the use of alcohol. The current study's results demonstrate that alcoholism therapy should become more integrated in SUD treatment, particularly with participants with severe CD. It is of interest to report that despite established differences in drug use and ASI composite improvement, effect sizes generally demonstrate that the role of CD severity is a small, albeit meaningful, variable in SUD treatment outcome. ASI composite scores and drug use at the start of treatment played a far larger role in predicting their respective post-treatment impairment than did CD severity. For instance, increased CD symptoms accounts for just 2\% of the variability of post-treatment psychiatric impairment, independent of intake scores. However, within this population, the results illustrate the need to provide enhanced treatment for clients presenting with high levels of impairment, independent of CD severity.

General conclusions. Although much is still unknown about CD severity and substance abuse treatment, it may be a broad measure of the disorder's detrimental effects. If so, it may 
behave similarly to depression or anxiety, where clients entering treatment with higher levels of impairment (Beutler, Blatt, Alimohamed, Levy, \& Angtuaco, 2006) or disorder severity

(Newman, Crits-Christoph, Gibbons, \& Erickson, 2006), respectively, are less likely to improve with treatment. It is likely that assessing the more intricate details of $\mathrm{CD}$ will provide more insight to the most effective form of SUD treatment.

\section{Prior Violent Behavior}

The final analyses were conducted to examine any differences in treatment outcome among participants classified as violent or nonviolent $\mathrm{CD}$. That is, among participants with $\mathrm{CD}$, the distinction was based upon reporting at least one symptom from the aggression subgroup as listed by the DSM-IV (APA, 2000). In short, no significant differences were found in terms of the comparison groups' response to treatment. There were, however, initial differences between the groups as ascertained by self-report at intake. Prior to treatment, employment/support ASI composite scores of the participants with violent $\mathrm{CD}$ was higher and the psychiatric composite lower than their nonviolent counterparts. Additionally, participants with violent CD used cocaine less often than participants with nonviolent CD prior to intake. Additionally, participants classified with violent $\mathrm{CD}$ had considerably more CD symptoms than those classified with nonviolent $\mathrm{CD}$. Such a result demonstrates that a history of violent behavior may be indicative of increased CD-related impairment.

ASI scores and drug use. As seen in comparing participants with and without a history of $\mathrm{CD}$, the group presumed to be more impaired fittingly scored higher on the employment/support composite of the ASI at intake. Violent behavior, in addition to the interpersonal difficulties that may be associated with $\mathrm{CD}$, appears to lower the likelihood of being hired for a job, retaining such a job, and supporting one's self. The results regarding the psychiatric composite of the ASI 
were more unexpected. Given that the violent CD participants not only had a history of aggression, but also significantly more $\mathrm{CD}$ symptoms than the nonviolent $\mathrm{CD}$ group, it would be expected that the violent $\mathrm{CD}$ group is more psychiatrically impaired. However, at intake, the nonviolent $\mathrm{CD}$ group presented with higher psychiatric composite scores. A possible explanation may lie in the psychiatric composite queries of various psychological symptoms outside of the realm of $\mathrm{CD}$ and aggression. Whereas a violent individual may assume his or her impairment lies within his or her aggression, nonviolent participants may be more likely to attribute their behavioral and cognitive deficits more accurately. In other words, one who does not act violently may be better suited to attribute impairment to anxiety or depression. Participants with violent CD may be more impaired than the nonviolent group, but the self-reporting nature of the ASI produces results that do not suggest the presence of severe problems. As discussed above, the effect of financial difficulties may play a part in the presenting differences in cocaine use.

General conclusions. Despite some differences prior to treatment, no differences were found in regards to treatment outcome or functioning. Whether an individual with $\mathrm{CD}$ had a history of aggression or not, improvement, as measured by ASI scores, drug use, treatment retention, and urine analyses, did not vary statistically over the course of treatment. While substance abusers with violent $\mathrm{CD}$ did differ at intake from those with nonviolent $\mathrm{CD}$ in terms of number of CD symptoms, employment/support composite scores, and recent cocaine use, the participants' response to treatment remained similar. Such results demonstrate that substance abuse treatment of a client with CD may not need to be adjusted based upon the client's prior violent behavior. Establishing a diagnosis of $\mathrm{CD}$ and its severity appears to be sufficient in determining necessary adjustments to one's SUD treatment techniques. Such a procedure does not appear to be excessively demanding and, given the current study's results, may be helpful in 
improving the target areas of treatment. Within this population, it seems that further analysis of one's $\mathrm{CD}$, in terms of topography of symptoms, may not be necessary in order to improve treatment efficacy.

\section{Limitations}

The most noticeable and detrimental limitation of the current study was the dropout rate among the participants. Of 105 initial consenters, only 50 participated in the full, 16-week study. Although the population of severe drug abusers appears to be a difficult one to retain over an extended period of time, relatively high dropout rates nevertheless likely altered the results and possible conclusions. Secondly, given the conservative method of the return-to-baseline missing data imputation, differences between comparison groups may have been minimized. Perhaps data could have been taken at more frequent intervals, as opposed to only three times over the course of the study. Additionally, in the absence of comprehensive ADHD measures, it was difficult to provide conclusive support for the theory that certain drugs, such as amphetamines, may aid ADHD symptoms through their use. Rather, it was inferred that it was likely some participants, due to a $\mathrm{CD}$ diagnosis, may also qualify for an $\mathrm{ADHD}$ diagnosis. With conclusive ADHD assessments, the presence of ADHD and its severity could be confirmed and not presumed.

Results may have differed if another missing data replacement method, such as mean substitution or last observation carried forward, was implemented. Some of the results approached but did not reach significance. Although much of the discussion involved the implications of data trends $(\mathrm{p} \leq .10)$, given the highly conservative method of data imputation, there is more confidence in the differences that were found. Perhaps with a less conservative approach, more group differences would achieve accepted levels of significance. It is also 
believed that additional participants and/or improved dropout rates would more decisively bring about significant results where the current results only approach significance. Lastly, there was no long-term follow up data collected. The final data point is the end of treatment- -16 weeks following intake - and it is unknown of any long-term changes in functioning among the participants. With additional longitudinal data collection, differences between comparison groups would be apparent and provide additional conclusions regarding SUD treatment outcome. Lastly, the use of a retrospective report to self-assess for childhood CD symptoms may lack optimal validity. Asking one to provide information about specific behaviors that may have occurred decades ago, particularly among an opioid dependent population, is not nearly as accurate as tracking the target behaviors as they occur. Although given the present study's access to the respective population, a diagnostic interview may have been feasible and efficient, it is not as compelling as other possible data collection methods.

\section{Conclusions}

The present results suggest that there are underlying differences within the population of treatment seeking, substance abusing adults based upon CD diagnosis, its severity, and prior violent behavior. Although multiple differences were found among the various comparison groups' ASI scores and drug use, two measures, treatment retention and urine analyses detecting the presence of various drugs, did not reveal any differences among any of the comparison groups. This may discredit any perceptions that participants with CD, regardless of its severity or prior aggressive behavior, will dropout of treatment earlier than others. It seems that a history of CD-related behavior may be irrelevant when concerning the treatment retention of an opioid dependent adult will remain in treatment. Such a measure, if interpreted in and of itself, may be misleading in revealing no differences between comparison groups. The urine analyses mainly 
dealt with the presence of opioids in the body and were tested three times each week. Once each week, a different, randomly selected drug was assessed for as well. As confirmed by urine analyses, there were no physiological differences regarding the examined drug use. Such a result demonstrates that utilizing urine analyses for the presence of drugs may not suffice as the sole measure of impairment. Perhaps future drug treatment programs are better served to use alternative measures of substance abuse in addition to the physiological detection of recent drug use. As differences in ASI scores demonstrate, there remains drug-related impairment within this population despite all indications from urine analyses. Urine sample analyses are one of many methods which can be useful in determining if deficits are present. However, given the contradictory results between urine sample analyses and other measures of similar constructs, it can be inferred that urine analyses, in and of itself, does not provide a comprehensive assessment of drug-related impairment with this population.

The current study examined the effects of CD on SUD treatment involving a severe, substance abusing population and offers a retrospective look as to how CD may be associated with improvement. In regards to the study's implications, it is the hope that the results provide insight into creating more effective SUD prevention and treatment programs. Higher summed ASI composites, psychiatric symptoms, amphetamine and alcohol intoxication rates, and the presenting deficiencies in the employment/support domain as a result of $\mathrm{CD}$ and its increased severity are all findings which could impact SUD treatment. Additionally, further examining why participants expected to be more impaired (e.g., a CD diagnosis, higher $\mathrm{CD}$ intensity) were more likely to improve in regards to cocaine use may also prove helpful. In examining SUD treatment, studies can build upon the present one by scrutinizing optimal treatment options, such as a focus on alcohol intoxication reduction or employment skill instruction. These minor 
additions to standard treatment protocol may be adequate to improve the treatment outcome of clients with $\mathrm{CD}$ or high $\mathrm{CD}$ severity. Further research is required, however, before such changes are put into practice. Possibly the most important contribution to the current literature is the recognition that $\mathrm{CD}$ is a complex disorder which affects the development and treatment of SUD. A better understanding of this relation and modifying SUD treatment accordingly will likely improve treatment efficacy and increase the probability of improvement within this population. 


\section{References}

Abracen, J., Looman, J., \& Anderson, D. (2000). Alcohol and drug abuse in sexual and nonsexual violent offenders. Sexual Abuse: A Journal of Research and Treatment, 12, 263-274.

Amass, L., Kamien, J.B., Branstetter, S.A. and Mikulich, S.K. (2000). A controlled comparison of the buprenorphine naloxone tablet and methadone for opioid maintenance treatment: Interim results. In: Harris, L.S., (Ed.), Problems of Drug Dependence, NIDA Research Monograph no. 180. Washington DC: U.S. Government Printing Office.

American Psychiatric Association (2000). Diagnostic and statistical manual of mental disorders (4th ed., text rev.). Washington, DC.

Appleby, L., Dyson, V., Altman, E., \& Luchins, D.J. (1997). Assessing substance use in multiproblem patients: Reliability and validity of the Addiction Severity Index in a mental hospital population. Journal of Nervous and Mental Disease, 185, 159-65.

Armstrong, T.D., \& Costello, E.J. (2002). Community studies on adolescent substance use, abuse, or dependence and psychiatric comorbidity. Journal of Consulting and Clinical Psychology, 70, 1224-1239.

Behrens, J.T. (1997). Principles and procedures of exploratory data analysis. American Psychological Association, 2, 131-160.

Beutler, L.E., Blatt, S.J., Alimohamed, S., Levy, K.N., \& Angtuaco, L.A. (2006). Participant factors in treating dysphoric disorders. In L.G. Castonguay, \& L.E. Beutler (Eds.), Principles of therapeutic change that work (pp. 13-82). New York: Oxford University Press.

Boyle, M.H., Offord, D.R., Racine, Y.A., Szatmari, P., Fleming, J.E., \& Links, P.S. (1992). 
Predicting substance use in late adolescence: Results from the Ontario Child Health Study follow-up. The American Journal of Psychiatry, 149, 761-767.

Brennan, T., Hulzinga, D., \& Elliot, D.S. (1978). The social psychology of runaways. Boston: D.C. Health \& Co.

Brook, J.S., Whiteman, M., Finch, S.J., \& Cohen, P. (1996). Young adult drug use and delinquency: Childhood antecedents and adolescent mediators. Journal of the American Academy of Child and Adolescent Psychiatry, 35, 1584-1592.

Brown, T.N., Schulenberg, J., Bachman, J.G., O’Malley, P.M., \& Johnston, L.D. (2001). Are risk and protective factors for substance use consistent across historical time? National data from the high school classes of 1976 through 1997. Prevention Science, 2, 29-43.

Burr, A. (1987). Chasing the dragon: Heroin misuse, delinquency and crime in the context of South London culture. The British Journal of Criminology, 27, 333-357.

Cleveland, M.M. (2006). Economics of illegal drug markets: What happens if we downsize the drug war? In J.M. Fish (Ed.), Drugs and society: U.S. public policy (pp. 173-200). Lanham, MD: Rowman \& Littlefield.

Crowley, T.J., Mikulich, S.K., MacDonald, M., Young, S.E., \& Zerbe, G.O. (1998). Substancedependent, conduct-disordered males: Severity of diagnosis predicts 2-year outcome. Drug and Alcohol Dependence, 49, 225-237.

Darke, S., Kaye, S., \& Finlay-Jones, R. (1998). Antisocial personality disorder, psychopathy and injecting heroin use. Drug and Alcohol Dependence, 52, 63-69.

Disney, E.R., Elkins, I.J., McGue, M., \& Iacono, W.G. (1999). Effects of ADHD, conduct disorder, and gender on substance use and abuse in adolescence. American Journal of Psychiatry, 156, 1515-1521. 
Duncan T.E., Duncan, S.C., \& Strycker, L.A. (2006). An introduction to latent variable growth curve modeling: Concepts, issues, and applications ( $2^{\text {nd }}$ ed.). Mahwah, NJ: Lawrence Eribaum Associates, Inc.

Engels, J.M., \& Diehr, P. (2003). Imputation of missing longitudinal data: A comparison of methods. Journal of Clinical Epidemiology, 56, 968-976.

Fergusson, D.M., Horwood, L.J., \& Ridder, E.M. (2005). Show me the child at seven: The consequences of conduct problems in childhood for psychosocial functioning in adulthood. Journal of Child Psychology and Psychiatry, 46, 837-849.

Fergusson, D.M., Lynskey, M.T., \& Horwood, L.J. (1993). Conduct problems and attention deficit behaviour in middle childhood and cannabis use by age 15. Australian and New Zealand Journal of Psychiatry, 27, 673-682.

Grella, C.E., Hser, Y., Joshi, V., \& Rounds-Bryant, J. (2001). Drug treatment outcomes for adolescents with comorbid mental and substance use disorders. Journal of Nervous and Mental Disease, 189, 384-392.

Helzer, J.E., Robins, L.N., McEvoy, L.T., Spitznagel, E.L., Stolzman, R.K., Farmer, A., \& Brockington, I.F. (1985). A comparison of clinical and Diagnostic Interview Schedule diagnoses. Physician reexamination of lay-interviewed cases in the general population. Archives of General Psychiatry, 42, 657-666.

Hodgins, D.C., \& el-Guebaly, N. (1992). Reliability and validity with the mentally ill substance abuser. Journal of Nervous and Mental Disease, 180, 197-201.

Hser, Y.I., Grella, C.E., Collins, C., \& Teruya, C. (2003). Drug-use initiation and conduct disorder among adolescents in drug treatment. Journal of Adolescence, 26, 331-345.

Hudziak, J.J., Helzer, J.E., Wetzel, M.W., Kessel, K.B., McGee, B., Janca, A., \& Przybeck, T. 
(1993). The use of the DSM-III-R checklist for initial diagnostic assessments. Comprehensive Psychiatry, 34, 375-383.

James, R.S., Sharp, W.S., Bastain, T.M., Lee. P.P., Walter, J.M., Czarnolewski, M., \& Castellanos, F.X. (2001). Double-blind, placebo-controlled study of single-dose amphetamine formulations in ADHD. Journal of the American Academy of Child \& Adolescent Psychiatry, 40, 1268-1276.

Janca, A., Robins, L.N., Bucholz, K.K., Early, T.S., \& Shayka, J.J. (1992). Comparison of the composite international diagnostic interview and clinical DSM-III-R criteria checklist diagnoses. Acta Psychiatrica Scaninavica, 85, 440-443.

Johnston, L.D., O’Malley, P.M., \& Eveland, L.K. (1978). Drug and delinquency: A search for causal connections. In D.B. Kandel (Ed.), Longitudinal research on drug use: Empirical findings and methodological issues (pp. 137-156). New York: John Wiley \& Sons.

Kellam, S.G., \& Brown, H. (1982). Social, adaptational, and psychological antecedents of adolescent psychopathology 10 years later. Baltimore: Johns Hopkins University.

King, G., Honaker, J., Joseph, A., \& Scheve, K. (1998, September). Listwise deletion is evil: What to do about missing data in political science. Paper presented at the Annual Meeting of the American Political Science Association, Boston, MA.

Lambert, N. (2005). The contribution of childhood ADHD, conduct problems, and stimulant treatment to adolescent and adult tobacco and psychoactive substance abuse. Ethical Human Psychology and Psychiatry, 7, 197-221.

Lewis, C.E., Robins, L.N., \& Rice, J. (1985). Association of alcoholism with antisocial personality in urban men. Journal of Nervous and Mental Disease, 173, 166-174.

Loeber, R., Green, S.M., Keenan, K., \& Lahey, B.B. (1995). Which boys will fare worse: Early 
predictors of the onset of conduct disorder in a six-year longitudinal study. American Academy of Child and Adolescent Psychiatry, 34, 499-509.

Mason, W.A., \& Windle, M. (2002). Reciprocal relations between adolescent substance use and delinquency: A longitudinal latent variable analysis. Journal of Abnormal Psychology, $111,63-76$.

McLellan, A.T., Kushner, H., Metzger, D., Peters, R., Smith, I. Grissom, G., Pettinati, H. et al. (1992). The fifth edition of the Addiction Severity Index. Journal of Substance Abuse Treatment, 9, 199-213.

McLellan, A.T., Luborsky, L., Cacciola, J., Evans, F., Barr, H.L., \& O’Brien, C.P. (1985). New data from the Addiction Severity Index. Reliability and validity in three centers. Journal of Nervous and Mental Disease, 173, 412-423.

McMahon, R.J., \& Wells, K.C. (1998). Conduct Problems. In E.J. Mash, \& R.A. Barkley (Eds.), Treatment of Childhood Disorders (2n ${ }^{\text {nd }}$ ed.) (pp. 111-207). New York: The Guildford Press.

Miller, P., \& Plant, M. (1999). Truancy and perceived school performance: An alcohol and drug study of UK teenagers. Alcohol \& Alcoholism, 34, 886-893.

Myers, M.G., Brown, S.A., \& Mott, M.A. (1995). Preadolescent conduct disorder behaviors predict relapse and progression of addiction for alcohol and drug abusers. Alcoholism: Clinical and Experimental Research, 19, 1528-1536.

Newman, M.G., Crits-Christoph, P., Gibbons, M.B., \& Erickson, T.M. (2006). Participant factors in treating dysphoric disorders. In L.G. Castonguay, \& L.E. Beutler (Eds.), Principles of therapeutic change that work (pp. 121-154). New York: Oxford University Press. 
O’Donnell, J., Hawkins, J.D., \& Abbott, R.D. (1995). Predicting serious delinquency and substance use among aggressive boys. Journal of Consulting and Clinical Psychology, $63,529-537$.

Reebye, P., Moretti, M.M., \& Lessard, J.C. (1995). Conduct disorder and substance use disorder: Comorbidity in a clinical sample of preadolescents and adolescents. Canadian Journal of Psychiatry, 40, 313-319.

Ridenour, T.A., Cottler, L.B., Robins, L.N., Compton, W.M., Spitznagel, E.L., \& CunninghamWilliams, R.M. (2002). Test of plausibility of adolescent substance use playing a causal role in developing adulthood antisocial behavior. Journal of Abnormal Psychology, 111, $144-155$.

Robins, L.N., Cottler, L.B., Bucholz, K.K., Compton, W.M., \& Rourke, K.M. (2000). Diagnostic Interview Schedule for the DSM-IV. St Louis: Washington University.

Simonoff, E., Elander, J., Holmshaw, J., Pickles, A., Murray, R., \& Rutter, M. (2004). Predictors of antisocial personality: Continuities from childhood to adult life. British Journal of Psychiatry, 184, 118-127.

Substance Abuse and Mental Health Services Administration. (2005). Results from the 2004 National Survey on Drug Use and Health: National Findings. Rockville, MD: Office of Applied Studies.

Tomlinson, K.L., Brown, S.A., \& Abrantes, A. (2004). Psychiatric comorbidity and substance use treatment outcomes of adolescents. Psychology of Addictive Behaviors, 18, 160-169.

White, H.R., Brick, J., \& Hansell, S. (1993). Alcohol use and aggression among youth. Alcohol Health \& Research World, 17, 144-150.

Whitmore, E.A., Mikulich, S.K., Ehlers, K.M., \& Crowley, T.J. (2000). One-year outcome of 
adolescent females referred for conduct disorder and substance abuse/dependence. Drug and Alcohol Dependence, 59, 131-141.

Windle, M. (1990). A longitudinal study of antisocial behaviors in early adolescence as predictors of late adolescent substance use: Gender and ethnic group differences. Journal of Abnormal Psychology, 99, 86-91.

Wise, B.K., Cuffe, S.P., \& Fischer, T. (2001). Dual diagnosis and successful participation of adolescents in substance abuse treatment. Journal of Substance Abuse Treatment, 21, 161-165.

Zoccolillo, M., Paquette, D., Azar, R., Cote, S., \& Tremblay R. (2004). Parenting as an important outcome of conduct disorder in girls. In M. Putallaz, \& K.L. Bierman (Eds.), Aggression, antisocial behavior, and violence among girls: A developmental perspective (pp. 242261). New York: Guilford Publications, Inc. 
Table 1.

Repeated-measures ANOVA of ASI composite scores over treatment, based upon CD diagnosis

\begin{tabular}{|c|c|c|c|}
\hline & $\begin{array}{l}\text { Intake } \\
M(S D)\end{array}$ & $\begin{array}{l}8 \text { weeks } \\
M(S D)\end{array}$ & $\begin{array}{c}16 \text { weeks } \\
M(S D)\end{array}$ \\
\hline \multicolumn{4}{|l|}{ Medical } \\
\hline No CD $(n=42)$ & $.32(.38)$ & $.33(.40)$ & $.29(.35)$ \\
\hline $\mathrm{CD}(n=63)$ & $.24(.31)$ & $.23(.31)$ & $.25(.31)$ \\
\hline \multicolumn{4}{|l|}{ Employment/support } \\
\hline No CD & $.54(.29)^{*}$ & $.44(.27)$ & $.47(.29)$ \\
\hline $\mathrm{CD}$ & $.64(.30)^{*}$ & $.57(.32)$ & $.61(.32)$ \\
\hline \multicolumn{4}{|l|}{ Alcohol use } \\
\hline No CD & $.09(.11)$ & $.08(.10)$ & $.07(.09)$ \\
\hline $\mathrm{CD}$ & $.09(.12)$ & $.07(.09)$ & $.07(.10)$ \\
\hline \multicolumn{4}{|l|}{ Drug use } \\
\hline No CD & $.24(.11)$ & $.20(.14)$ & $.18(.13)$ \\
\hline $\mathrm{CD}$ & $.24(.12)$ & $.18(.13)$ & $.19(.13)$ \\
\hline \multicolumn{4}{|l|}{ Legal } \\
\hline No CD & $.18(.20)$ & $.14(.19)$ & $.12(.16)$ \\
\hline $\mathrm{CD}$ & $.17(.21)$ & $.12(.18)$ & $.11(.14)$ \\
\hline \multicolumn{4}{|c|}{ Family/social relationships } \\
\hline No CD & $.19(.20)$ & $.22(.18)$ & $.20(.19)$ \\
\hline $\mathrm{CD}$ & $.21(.21)$ & $.23(.17)$ & $.23(17)$ \\
\hline \multicolumn{4}{|l|}{ Psychiatric } \\
\hline No CD & $.13(.19)$ & $.14(.17)$ & $.12(.15)$ \\
\hline $\mathrm{CD}$ & $.14(.17)$ & $.15(.17)$ & $.17(.17)$ \\
\hline \multicolumn{4}{|l|}{ ASI Sum score* } \\
\hline No CD & $1.67(.83)$ & $1.55(.79)$ & $1.43(.76)$ \\
\hline $\mathrm{CD}$ & $1.73(.70)$ & $1.56(.67)$ & $1.62(.63)$ \\
\hline
\end{tabular}


Table 2.

Repeated-measures ANOVA of drug use over the past 30 days based upon CD diagnosis (raw data)

\begin{tabular}{|c|c|c|c|}
\hline & $\begin{array}{l}\text { Intake } \\
M(S D)\end{array}$ & $\begin{array}{l}8 \text { weeks } \\
M(S D)\end{array}$ & $\begin{array}{l}16 \text { weeks } \\
M(S D)\end{array}$ \\
\hline \multicolumn{4}{|c|}{ Alcohol (days consumed) } \\
\hline No $C D(n=42)$ & $6.83(8.84)$ & $7.55(10.16)$ & $5.90(8.08)$ \\
\hline $\mathrm{CD}(n=63)$ & $5.57(9.10)$ & $5.33(9.00)$ & $4.92(8.10)$ \\
\hline \multicolumn{4}{|l|}{ Alcohol intoxication } \\
\hline No $C D$ & $2.62(6.84)$ & $1.98(5.29)$ & $1.38(4.47)$ \\
\hline $\mathrm{CD}$ & $2.51(6.43)$ & $1.40(4.28)$ & $1.67(4.83)$ \\
\hline \multicolumn{4}{|l|}{ Heroin } \\
\hline No $C D$ & $25.43(7.84)$ & $15.21(13.15)$ & $15.00(32.36)$ \\
\hline $\mathrm{CD}$ & $25.27(9.85)$ & $15.83(13.67)$ & $16.51(13.62)$ \\
\hline \multicolumn{4}{|l|}{ Methadone } \\
\hline No CD & $3.17(8.07)$ & $2.05(7.07)$ & $1.33(5.52)$ \\
\hline $\mathrm{CD}$ & $5.00(10.20)$ & $1.94(6.65)$ & $2.41(7.53)$ \\
\hline \multicolumn{4}{|l|}{ Opiates } \\
\hline No $C D$ & $1.92(6.48)$ & $1.24(4.17)$ & $1.29(3.83)$ \\
\hline $\mathrm{CD}$ & $1.53(5.67)$ & $1.42(5.43)$ & $.76(3.89)$ \\
\hline \multicolumn{4}{|l|}{ Barbiturates } \\
\hline No $C D$ & $.00(.00)$ & $.00(.00)$ & $.02(.15)$ \\
\hline $\mathrm{CD}$ & $.16(.96)$ & $.18(.97)$ & $.42(2.12)$ \\
\hline \multicolumn{4}{|l|}{ Sedatives } \\
\hline No $C D$ & $.98(3.53)^{*}$ & $1.48(4.16)$ & $1.93(5.74)$ \\
\hline $\mathrm{CD}$ & $.35(2.09)^{*}$ & $.27(1.30)$ & $.26(1.10)$ \\
\hline \multicolumn{4}{|l|}{ Cocaine** } \\
\hline No CD & $2.83(6.36)$ & $3.62(6.90)$ & $2.95(5.91)$ \\
\hline $\mathrm{CD}$ & $3.98(6.54)$ & $3.03(6.22)$ & $2.75(5.96)$ \\
\hline \multicolumn{4}{|l|}{ Amphetamines* } \\
\hline No $C D$ & $.48(1.95)$ & $1.07(4.57)$ & $.95(4.84)$ \\
\hline $\mathrm{CD}$ & $.11(.48)$ & $.11(.48)$ & $.17(.64)$ \\
\hline \multicolumn{4}{|l|}{ Marijuana } \\
\hline No $C D$ & $4.43(8.60)$ & $5.24(9.34)$ & $4.52(8.78)$ \\
\hline $\mathrm{CD}$ & $5.25(8.71)$ & $4.73(7.95)$ & $5.46(9.15)$ \\
\hline \multicolumn{4}{|l|}{ Hallucinogens } \\
\hline No CD & $.00(.00)$ & $.00(.00)$ & $.00(.00)$ \\
\hline $\mathrm{CD}$ & $.00(.00)$ & $.02(.13)$ & $.06(.50)$ \\
\hline \multicolumn{4}{|l|}{ Multiple drugs } \\
\hline No CD & $9.86(10.51)$ & $8.38(10.33)$ & $6.88(9.87)$ \\
\hline CD & $10.67(10.76)$ & $6.86(8.82)$ & $6.49(8.52)$ \\
\hline
\end{tabular}

$* p \leq .10 ; * * p \leq .05$ 
Table 3 .

Hierarchical multiple regression of CD severity and ASI composite scores, controlling for intake scores

\begin{tabular}{lccc}
\hline \multicolumn{1}{c}{ ASI composite } & $\beta$ & Final Model $R^{2}$ & $R^{2}$ change \\
\hline Medical & -.05 & .55 & .00 \\
Employment/support & .07 & .72 & .01 \\
Alcohol & .01 & .74 & .00 \\
Drugs & .09 & .38 & .01 \\
Legal & .01 & .52 & .00 \\
Family/social relationships & .08 & .35 & .01 \\
Psychiatric & .13 & .58 & $.02 * *$ \\
ASI Sum score & .09 & .64 & .01 \\
\hline
\end{tabular}

** $p \leq .05$ 
Table 4.

Hierarchical multiple regression of $C D$ severity and days of drug use over the past 30 days, controlling for use at intake

\begin{tabular}{lccc}
\hline \multicolumn{1}{c}{ Drug } & $\beta$ & $R^{2}$ & $R^{2}$ change \\
\hline Alcohol & .01 & .70 & .00 \\
Alcohol intoxication & .17 & .52 & $.03 * * *$ \\
Heroin & .10 & .21 & .01 \\
Methadone & .12 & .40 & .02 \\
Opiates & -.08 & .33 & .01 \\
Barbiturates & -.09 & .40 & .01 \\
Sedatives & -.14 & .34 & $.02^{*}$ \\
Cocaine & -.12 & .52 & $.01^{*}$ \\
Amphetamines & .00 & .41 & .00 \\
Marijuana & .03 & .80 & .00 \\
Multiple drugs & .02 & .46 & .00 \\
\hline
\end{tabular}

$* p \leq .10 ; * * p \leq .05 ; * * * p \leq .01$ 
Table 5 .

Repeated measures ANOVA of ASI composite scores based upon prior violent, CD-related behavior

\begin{tabular}{|c|c|c|c|}
\hline & $\begin{array}{c}\text { Intake } \\
M(S D)\end{array}$ & $\begin{array}{l}8 \text { weeks } \\
M(S D)\end{array}$ & $\begin{array}{c}16 \text { weeks } \\
M(S D)\end{array}$ \\
\hline \multicolumn{4}{|l|}{ Medical } \\
\hline Nonviolent CD $(n=24)$ & $.20(.27)$ & $.20(.26)$ & $.24(.27)$ \\
\hline Violent CD $(n=39)$ & $.25(.32)$ & $.24(.33)$ & $.24(.31)$ \\
\hline \multicolumn{4}{|l|}{ Employment/support } \\
\hline Nonviolent CD & $.53(.35)^{* *}$ & $.47(.36)$ & $.49(.35)$ \\
\hline Violent CD & $.69(.26)^{* *}$ & $.62(.28)$ & $.67(.28)$ \\
\hline \multicolumn{4}{|l|}{ Alcohol use } \\
\hline Nonviolent CD & $.07(.10)$ & $.06(.09)$ & $.07(.09)$ \\
\hline Violent CD & $.10(.13)$ & $.08(.10)$ & $.08(.10)$ \\
\hline \multicolumn{4}{|l|}{ Drug use } \\
\hline Nonviolent CD & $.26(.23)$ & $.19(.12)$ & $.19(.10)$ \\
\hline Violent CD & $.23(12)$ & $.18(.13)$ & $.19(.13)$ \\
\hline \multicolumn{4}{|l|}{ Legal } \\
\hline Nonviolent CD & $.12(.20)$ & $.11(.17)$ & $.09(.13)$ \\
\hline Violent CD & $.20(22)$ & $.13(.19)$ & $.12(.15)$ \\
\hline \multicolumn{4}{|l|}{ Family/social relationships } \\
\hline Nonviolent CD & $.26(.23)$ & $.23(.19)$ & $.23(.17)$ \\
\hline Violent CD & $.19(.19)$ & $.23(.19)$ & $.23(.17)$ \\
\hline \multicolumn{4}{|l|}{ Psychiatric } \\
\hline Nonviolent CD & $.19(.17)^{*}$ & $.20(.15)$ & $.19(.15)$ \\
\hline Violent CD & $.11(.16)^{*}$ & $.13(.17)$ & $.15(.18)$ \\
\hline \multicolumn{4}{|l|}{ ASI Sum score } \\
\hline Nonviolent CD & $1.63(.85)$ & $1.47(.69)$ & $1.49(.62)$ \\
\hline Violent CD & $1.77(.70)$ & $1.61(.66)$ & $1.67(.62)$ \\
\hline
\end{tabular}


Table 6.

Repeated measures ANOVA of drug use over the past 30 days based upon prior violent, CDrelated behavior (raw data)

\begin{tabular}{|c|c|c|c|}
\hline & $\begin{array}{c}\text { Intake } \\
M(S D)\end{array}$ & $\begin{array}{l}8 \text { weeks } \\
M(S D)\end{array}$ & $\begin{array}{c}16 \text { weeks } \\
M(S D)\end{array}$ \\
\hline \multicolumn{4}{|l|}{ Alcohol (days consumed) } \\
\hline Nonviolent CD $(n=24)$ & $3.96(7.45)$ & $4.70(8.36)$ & $4.48(6.99)$ \\
\hline Violent CD $(n=39)$ & $6.67(9.97)$ & $5.85(9.46)$ & $5.31(8.82)$ \\
\hline \multicolumn{4}{|l|}{ Alcohol intoxication } \\
\hline Nonviolent CD & $1.04(3.15)$ & $.48(1.20)$ & $.35(.65)$ \\
\hline Violent CD & $3.44(7.70)$ & $1.97(5.31)$ & $2.49(6.00)$ \\
\hline \multicolumn{4}{|l|}{ Heroin } \\
\hline Nonviolent CD & $26.26(7.71)$ & $15.96(13.63)$ & $16.91(13.26)$ \\
\hline Violent CD & $24.56(11.05)$ & $15.90(14.02)$ & $16.69(13.91)$ \\
\hline \multicolumn{4}{|l|}{ Methadone } \\
\hline Nonviolent CD & $6.48(11.79)$ & $.00(.00)$ & $2.61(8.64)$ \\
\hline Violent CD & $4.23(9.33)$ & $3.12(8.27)$ & $2.36(7.01)$ \\
\hline \multicolumn{4}{|l|}{ Opiates } \\
\hline Nonviolent CD & $1.70(6.28)$ & $1.65(6.28)$ & $.39(1.20)$ \\
\hline Violent CD & $1.47(5.42)$ & $1.32(5.00)$ & $1.00(4.89)$ \\
\hline \multicolumn{4}{|l|}{ Barbiturates } \\
\hline Nonviolent CD & $.13(.63)$ & $.13(.63)$ & $.13(.63)$ \\
\hline Violent CD & $.18(1.14)$ & $.19(1.15)$ & $.61(2.66)$ \\
\hline \multicolumn{4}{|l|}{ Sedatives } \\
\hline Nonviolent CD & $.00(.00)$ & $.00(.00)$ & $.09(.29)$ \\
\hline Violent CD & $.58(2.66)$ & $.45(1.64)$ & $.24(1.15)$ \\
\hline \multicolumn{4}{|l|}{ Cocaine } \\
\hline Nonviolent CD & $5.30(6.70)^{*}$ & $3.91(6.13)$ & $2.78(5.13)$ \\
\hline Violent CD & $3.31(6.47)^{*}$ & $2.59(6.37)$ & $2.77(6.53)$ \\
\hline \multicolumn{4}{|l|}{ Amphetamines } \\
\hline Nonviolent CD & $.22(.67)$ & $.22(.67)$ & $.26(.75)$ \\
\hline Violent CD & $.05(.32)$ & $.05(.32)$ & $.13(.57)$ \\
\hline \multicolumn{4}{|l|}{ Marijuana } \\
\hline Nonviolent CD & $4.39(7.91)$ & $4.61(7.72)$ & $5.52(9.45)$ \\
\hline Violent CD & $5.90(9.28)$ & $4.90(8.26)$ & $5.44(9.21)$ \\
\hline \multicolumn{4}{|l|}{ Hallucinogens } \\
\hline Nonviolent CD & $.00(.00)$ & $.04(.21)$ & $.00(.00)$ \\
\hline Violent CD & $.00(.00)$ & $.00(.00)$ & $.10(.64)$ \\
\hline \multicolumn{4}{|l|}{ Multiple drugs } \\
\hline Nonviolent CD & $10.22(10.66)$ & $6.35(8.48)$ & $4.57(7.15)$ \\
\hline Violent CD & $11.21(10.94)$ & $7.33(9.16)$ & $7.79(9.16)$ \\
\hline
\end{tabular}

$* p \leq .10$ 


\section{MATTHEW E. GOLDFINE \\ CURRICULUM VITAE \\ VERSION DATE: 12/11/2006}

\section{PERSONAL}

$\begin{array}{ll}\text { Home address: } & 971 \text { Valley View Avenue } \\ & \text { Apartment 710 } \\ & \text { Morgantown, West Virginia 26505 } \\ & \text { (914)-629-1067 } \\ \text { Personal telephone: } & \text { West Virginia University } \\ \text { Department of Psychology } & \text { 2210 Life Science Building } \\ \text { Professional address: } & \text { 53 Campus Drive } \\ & \text { P.O. Box 6040 } \\ & \text { Morgantown, West Virginia 26506-6040 } \\ & \text { (304)-293-2001 } \\ & \text { (304)-293-6606 } \\ \text { Work telephone: } & \text { Matthew.Goldfine@mail.wvu.edu }\end{array}$

\section{EDUCATION HISTORY}

2006-present

2004-2006

2000-2004
West Virginia University (WVU), Morgantown, West Virginia Clinical Child Psychology Student Ph.D. (expected 8/2009)

Faculty Supervisor: Steven A. Branstetter, Ph.D.

West Virginia University (WVU), Morgantown, West Virginia Clinical Child Psychology Student M.S.: Conduct Disorder and future substance abuse: Factors affecting treatment outcome.

Thesis Chair: Steven A. Branstetter, Ph.D.

GPA: 4.0

\section{Binghamton University, State University of New York (BU-SUNY),} Binghamton, New York

B.A., Psychology; graduated magma cum laude

Research involved treatment of adults with anxiety due to previous trauma. Faculty Supervisor: Donald J. Levis, Ph.D.

GPA: 3.74

\section{CLINICAL EXPERIENCE}

Psychological Intern, Washington County Children Youth Services, 2006-2007 (WVU)
Provided psychological assessment and behavior therapy for adults, adolescents, and children. Responsibilities included evaluating termination of custodial rights, adolescent truancy, physical abuse, child neglect and physical/sexual abuse, assisting in court testimony, and general mental health evaluations. Assessment activities included diagnostic, personality, and intellectual assessments of children and adults to assist with the development of the family service plan.

Supervisor: Michael Crabtree, Ph.D. 
Graduate Student Therapist, Bereavement Treatment (Camp Nabe), 2006 (WVU)

Head Counselor, Summer Treatment Program (STP), 2005 (WVU)

Lead Coordinator, STP, 2005 (WVU)

Lead Coordinator, The School Assessment and Intervention Project (SAIP), 2005 (WVU)

Group Treatment Leader, SAIP, 2005 (WVU)
Co-led three grief treatment groups for 28 total children who recently lost a close family member or friend. Ages of clients ranged from 7-14 years. Also served as an on-call crisis therapist. Supervisor: N/A

Provided intensive behavior modification for six children and adolescents (ages 10-13) diagnosed with ADHD, ODD, CD, and Asperger's Syndrome. Responsibilities included 60 hours a week of assessment, behavior monitoring, and reinforcement based upon achievement of target behaviors. Additional responsibilities included two hours per week of parent training, child social skills training, composing detailed intake and exit reports, school consultations, and health and sports skill instruction.

Supervisor: Andy Lopez-Williams, Ph.D.

Established WVU as a site for a STP, an empirically supported treatment for children and adolescents with ADHD and other disruptive behaviors. Responsibilities included conducting comprehensive parental intake interviews, assessing child intelligence and achievement, and administering and reviewing parent, teacher, and child-self report measures on measures of anxiety, depression, ADHD, ODD, CD, and readiness for change. Supervisor: Andy Lopez-Williams, Ph.D.

Lead SAIP, a large-scale endeavor conducted in collaboration with three Monongalia County Schools whose aims were to assess and identify children at-risk for or currently exhibiting clinically impairing problems in daily functioning and to provide a host of evidencebased intervention services for over 900 children. Responsibilities included supervision and training of 18 undergraduate and graduate students, coordinating day-to-day activities, conducting psychological and social skills assessments, and supervising suicide assessments and behavior observations. Psychometric forms utilized included the CDI, MASC, SPAI-C, T-IRS, and various ADHD measures. Administrative duties included regular and periodic meetings with school counselors and the Monongalia County school superintendent and assistant superintendent, respectively.

Supervisors: Tracy L. Morris, Ph.D. and Andy Lopez-Williams, Ph.D.

Led two school-based treatment groups of anxiety and comorbid ADHD/anxiety with a total of 12 children in grades 3-5. The groups consisted of two sessions per week for six weeks. Responsibilities included attending weekly training meetings, conducting cognitivebehavioral treatment, contacting parents, and completing exit reports.

Supervisors: Tracy L. Morris, Ph.D. and Andy Lopez-Williams, Ph.D. 
Graduate Student

Therapist, 2004-2006

(WVU)

Peer Counseling and

Crisis Therapist, 2004

(BU-SUNY)

Student Therapist, Children's Unit for Treatment and Evaluation, 2001 (BUSUNY)
Conducted and co-conducted individual psychotherapy sessions as part of a Quin Curtis Center clinical team. Under Dr. LopezWilliams, clients included 14-16 year old adolescents with ADHD, their parents, and other family members. Under Dr. McNeil, clients included 2-7 year old children with disruptive behavior disorders. Responsibilities included conducting therapy sessions (face-to-face and by phone), completing intake, progress, and session tracking reports, administering assessment measures, HIPAA training, consultation with faculty supervisors and senior graduate students, and supervising junior graduate and undergraduate students. Supervisors: Andy Lopez-Williams, Ph.D. and Cheryl B. McNeil, Ph.D.

Served as a volunteer university crisis hotline operator. Clients included undergraduate college students and community members. Responsibilities included intensive training, "on call" weekly service in the crisis center including overnight shifts, and testing potential hotline operators.

Supervisor: Rosemary Ryan

Provided intense behavioral treatment and educational services for three autistic and developmentally disabled children utilizing an applied behavior analysis approach. Responsibilities included supervised implementation of an individualized treatment program, receiving training in behavior modification and autism, and presenting a case study of a child.

Supervisor: Raymond Romanczyk, Ph.D.

\section{RESEARCH EXPERIENCE}

Lab coordinator and Research Assistant, Adolescent Research Laboratory, 2005-2006 (WVU)

\section{Lab coordinator and Research Assistant, Children, Youth, and Families Program, 2004- 2005 (WVU)}

Primary responsibilities included coordination with a team of ten undergraduate and graduate students to examine decision-making, impulsivity, and the ability to delay rewards. Additional projects include a treatment outcome study for college alcohol users, a study of how childhood Conduct Disorder and Antisocial Personality Disorder affects treatment outcome among opiate users, and an ongoing study on parent and adolescent relationship factors influencing substance use.

Supervisor: Steven A. Branstetter, Ph.D.

Responsibilities included serving as the head coordinator of the STP and SAIP (clinical duties described above), interviewing and training undergraduate and graduate students, and attending weekly meetings. Projects included studying children with comorbid ADHD and anxiety, ADHD children and their overestimation of peer likeability (positive illusory biases), and the sociometric status of children and social interactions.

Supervisor: Andy Lopez-Williams, Ph.D. 
Research Assistant, Fear and Anxiety Laboratory, 2003-2004 (BU-SUNY)
Responsibilities included behavior coding and audio transcription of taped clinical treatment sessions involving Implosive and Brain Release Therapy, collecting, organizing and scoring sexual abuse questionnaires, and aiding a senior graduate student's thesis by aiding in random sampling, entering, and analyzing data, and creating lists and reports of information.

Supervisors: Donald J. Levis, Ph.D. and Patricia A. Rourke, Ph.D.

\section{TEACHING APPOINTMENTS}

Instructor, Introduction to Human Development, Spring 2006 (WVU)

Graduate Teaching
Assistant, Behavioral
Assessment II, Spring
2006 (WVU)
Guest Lecturer,
Exceptional Children, Fall
2005 (WVU)

Instructor, Introduction to Psychology, Fall 2004 (WVU)
Instructed 120 students over two sections for 50 minutes, three times a week at the undergraduate level. Responsibilities included conducting lectures, developing PowerPoint slides, exam construction, holding office hours, answering questions, monitoring exams, and calculating and entering final semester grades.

Supervisor: Matthew H. Scullin, Ph.D.

Assisted in a graduate class of six students. Responsibilities included supervising and grading students on administration of standardized intelligence measures (i.e., WISC).

Supervisor: Amy Fiske, Ph.D.

Created and presented an upper-level class lecture discussing the theories and causes of child behavior to a class of approximately 45 undergraduate students.

Supervisor: Andy Lopez-Williams, Ph.D.

Instructed 117 students for 75 minutes, twice a week at the undergraduate level. Responsibilities included conducting lectures, developing PowerPoint slides, answering questions, monitoring exams, and calculating/entering final semester grades.

Supervisors: Cheryl B. McNeil, Ph.D. and Jennifer A. Margrett, Ph.D.

Assisted in an undergraduate class of approximately 150 students. Responsibilities included proctoring and grading exams, posting grades, and attending lectures. Supervisor: Laura Cramer, M.A.

Assisted in an undergraduate class of approximately 200 students. Responsibilities included assisting in lecture presentation, holding office hours, proctoring and grading exams, and conducting review sessions.

Supervisor: Joseph Morrissey, Ph.D.

\section{PUBLICATIONS AND PRESENTATIONS}

Goldfine, M.E., Branstetter, S.A., \& Cottrell, L. Discourse comfort and communication style: A model toward optimal parental monitoring knowledge of adolescent risk behavior. Poster to be presented at the $33^{\text {rd }}$ biennial meeting of the Society for Research of Child Development, Boston, MA, 2007.

Grady, E.S., Goldfine, M.E., \& Branstetter, S.A. Comparing nine common methods of missing 
data imputation in longitudinal studies: Statistical analyses and latent growth models. Poster to be presented at the $33^{\text {rd }}$ biennial meeting of the Society for Research of Child Development, Boston, MA, 2007.

Goldfine, M.E., Branstetter, S.A., Kamien, J.B., \& Amass, L. (2006, November). Conduct Disorder and future substance abuse: A factor analysis of symptoms. Poster presented at the $40^{\text {th }}$ annual meeting of the Association for Behavioral and Cognitive Therapies, Chicago, IL.

Goldfine, M.E., Grady, E.S., Branstetter, S.A., Kamien, J.B., \& Amass, L. (2006, November). Antisocial Personality Disorder severity: Predictors among substance abusers seeking treatment. Poster presented at the $40^{\text {th }}$ annual meeting of the Association for Behavioral and Cognitive Therapies, Chicago, IL.

Grove, J.A., Goldfine, M.E., Ryan, L., Branstetter, S.A., Kamien, J.B., \& Amass, L. (2006, November). Gender differences in martial satisfaction and adults seeking treatment for a substance use disorder. Poster presented at the $40^{\text {th }}$ annual meeting of the Association for Behavioral and Cognitive Therapies, Chicago, IL.

Bailey, K.A., Goldfine, M.E., Branstetter, S.A., Kamien, J.B., \& Amass, L. (2006, November). Symptoms of depression discriminate between light versus heavy smokers. Poster presented at the $40^{\text {th }}$ annual meeting of the Association for Behavioral and Cognitive Therapies, Chicago, IL.

Rubino, T.M., Anderson, S.E., Goldfine, M.E., \& Branstetter, S.A. (2006, November). The effects of marijuana on sleep quality and duration. Poster presented at the $40^{\text {th }}$ annual meeting of the Association for Behavioral and Cognitive Therapies, Chicago, IL.

Grove, J.A., Goldfine, M.E., Branstetter, S.A., \& Cottrell, L. Parenting styles and adolescent perceptions of parental knowledge. Poster submitted for presentation at the annual West Virginia Psychology Association Conference, Canaan Valley, WV, 2006.

Goldfine, M.E. (2006, February). ADHD and comorbid anxiety and depression: Behavior modification as an effective treatment. Presented during the Clinical Case Conference for the Department of Clinical Psychology, West Virginia University, Morgantown, WV.

Goldfine, M., \& Lopez-Williams, A. (2005) Book review: Multisystemic Therapy and Neighborhood Partnerships: Reducing Adolescent Violence and Substance Abuse. The Behavior Therapist, 28, 86-87.

Foley, K.P., Goldfine, M.E., \& McNeil, C.B. (2005, November). Children and Domestic Violence: Your responsibilities as an educator. Poster presented at the $39^{\text {th }}$ annual meeting of the Association for Behavioral and Cognitive Therapies, Washington D.C.

Chorney, D.B., Morris, T.L., Lopez-Williams, A., \& Goldfine, M.E (2005, November). Social status and behaviors associated with comorbid ADHD and anxiety in children. Poster presented at the $39^{\text {th }}$ annual meeting of the Association for Behavioral and Cognitive Therapies, Washington D.C. 


\section{MANUSCRIPTS IN PREPARATION}

Goldfine, M.E., Evangelista, N.M., \& Owens, J.S (2006). ADHD and the positive illusory bias. Manuscript in preparation.

Goldfine, M.E., Wagner, S.M., \& McNeil, C.B. (2006). Parent Child Interaction Therapy: A costeffectiveness study. Manuscript in preparation.

Goldfine, M.E., Branstetter, S.A., Kamien, J.B., \& Amass, L. (2006). Conduct Disorder and future substance abuse: Factors affecting treatment outcome. Manuscript in preparation.

Goldfine, M.E., Foley, K.P., \& McNeil, C.B. (2006). Teaching evaluations: Making sense of it all. Manuscript in preparation.

\section{PROFESSIONAL MEMBERSHIPS}

Psi Chi, student member (1998-present)

Phi Beta Kappa, student member (1999-present)

Association of Behavioral and Cognitive Therapies, student member (2004-present)

American Psychological Association, student member (2005-present)

Society for Research of Child Development, student member (2006-present)

\section{ADDITIONAL SKILLS AND TRAINING}

Computer: SPSS, Microsoft Office (Word, Excel, PowerPoint), Dream Weaver website design program

Intelligence Measure Administration (WISC-IV, WAIS-III, WIAT-II)

Infant Development Administration (Bayley Scales of Infant Development-III)

Various Psychometric Test Administration (MASC, CDI, CBCL, DBD Rating Scale)

Crisis Hotline operator

Behavior Coding Certified

CPR, First Aid, and Lifeguard Certified

Working knowledge of Spanish

\section{AWARDS AND LEADERSHIP EXPERIENCES}

2006-2007

2006-2007

2005-2006

2005-2006

$2005-2006$

2005-2006

2005

2005-2006

2004-2005

2004

2003-2004

2000-2003
Wellness Committee, Graduate Student Representative

Safety Committee, Graduate Student Representative

Alumni Fund Research Award (WVU)

Full Faculty Committee, Graduate Student Representative (WVU)

Professional Research Milestone Award (WVU)

Eberly College of Arts and Sciences Graduate Student Travel Award (WVU)

Doctoral Student Travel Award (WVU)

Department of Psychology Travel Grant (WVU)

HERF: Higher Education Resource Fund Award (WVU)

Magma Cum Laude Graduate (BU-SUNY)

Treasurer of Psi Chi (BU-SUNY)

Dean's List (BU-SUNY) 


\section{REFERENCES}

Steven A. Branstetter, Ph.D.

Assistant Professor

West Virginia University

Department of Psychology

P.O. Box 6040

Morgantown, West Virginia 26506

Phone: (304)-293-2001, ext. 31644

E-mail: Steven.Branstetter@mail.wvu.edu

\section{Cheryl B. McNeil, Ph.D.}

Professor

West Virginia University

Department of Psychology

P. O. Box 6040

Morgantown, West Virginia 26506

Phone: (304)-293-2001, ext. 31677

E-mail: Cheryl.McNeil@mail.wvu.edu

Michael Crabtree, Ph.D.

Supervising Psychologist

Washington County Children Youth Services

Psychological Associates

87 E. Maiden Street

Washington, PA 15301

Phone: (724)-222-8525

E-mail: mcrabtree@washjeff.edu 